\title{
Transport of Soluble Species in Backfill and Rock
}

P. L. Chambre, W. W.-L. Lee, W. B. Light, and T. H. Pigford

\section{Department of Nuclear Engineering University of California}

\author{
and \\ Earth Sciences Division \\ Lawrence Berkeley Laboratory \\ University of California \\ One Cyclotron Road \\ Berkeley, CA 94720
}

\author{
March 1992
}

Work supported by the Director, Office of Civilian Radioactive Waste Management, Yucca Mountain Site Characterization Project Office, of the U.S. Department of Energy under contract DE-AC03-76SF00098. 
The authors invite comments and would appreclate being notified of any errors in the report.

T. H. Pigford

Department of Nuclear Engineering

University of Callfornia

Berkeley, CA 94720

"Prepared by Yucca Mountain Site Characterization Project (YMSCP) participants as part of the Civilian Radioactive Waste Management Program (CRWM). The YMSCP is managed by the Yucca Mountain Project Office of the U. S. Department of Energy, DOE Field Office, Neveda (DOE/NV). YMSCP work is sponsored by the Office of Geologic Repositories (OGR) of the DOE Office of Civilian Radioactive Waste Management (OCRWM)." 


\section{CONTENTS}

1. INTRODUCTION . . . . . . . . . . . . . . . . . . . . . . . . . . . . . . . . . . . . . 1

2. DISSOLUTION OF FISSION PRODUCT SPECIES . . . . . . . . . . . . . . . . . . . . . . 1

3. ANALYSIS . . . . . . . . . . . . . . . . . . . . . . . . . . . . . . . 2

3.1 TRANSPORT OF SOLUBLE SPECIES INTO BACKFILL AND ROCK . . . . . . . . . . 2

3.2 TRANSPORT OF SOLUBLE SPECIES INTO ROCK . . . . . . . . . . . . . . . . . . 8

4. NUMERICAL ILLUSTRATIONS . . . . . . . . . . . . . . . . . . . . . . . . . . . . . 9

5. CONCLUSIONS .............................. 16

REFERENCES . . . . . . . . . . . . . . . . . . . . . . . . 16

TABLES

Table I. Waste Package Dimensions, Spent Fuel from Pressurized Water Reactors . . . . . . . . . 10

Table II. Rock Properties . . . . . . . . . . . . . . . . . . . . . . . . . . . . . . . . . 10

Table III. Characteristics of the Nuclides Studied . . . . . . . . . . . . . . . . . . . . . 10

\section{FIGURES}

Fig. 1. Typical Waste Package Cross Section. . . . . . . . . . . . . . . . . . . . . . . . . . 3

Fig. 2. Release of soluble species into backfill and rock. . . . . . . . . . . . . . . . . . . . 4

Fig. 3. Release of soluble species into rock. . . . . . . . . . . . . . . . . . . . . . . . . . . . . . . 8

Fig. 4. Fractional release rates of ${ }^{99} \mathrm{Tc},{ }^{135} \mathrm{Cs},{ }^{137} \mathrm{Cs}$ and ${ }^{129} \mathrm{I}$ through $30 \mathrm{~cm}$ of backfill, at the backfill/rock interface, normalized to initial inventory . . . . . . . . . . . . . . . . . . 12

Fig. 5. Fractional release rate of ${ }^{99} \mathrm{Tc}$, normalized to its initial inventory, as a function of time and backfill thickness. . . . . . . . . . . . . . . . . . . . 13

Fig. 6. Gap and matrix fractional release rates of ${ }^{99} \mathrm{Tc},{ }^{135} \mathrm{Cs},{ }^{137} \mathrm{Cs}$ and ${ }^{129} \mathrm{I}$ directly into rock as a function of time. 


\section{INTRODUCTYON}

In this report we study the release and transport of soluble species from spent nuclear fuel. By soluble species we mean a fraction of certain fission product species. Our previously developed methods for calculating release rates of solubility-limited species [Chambré et al. 1982; 1985] need to be revised for these soluble species. Here we provide methods of calculating release rates of soluble species directly into rock and into backfill and then into rock.

Section 2 gives a brief discussion of the physics of fission products dissolution from $\mathrm{UO}_{2}$ spent fuel. Section 3 presents the mathematics for calculating release rates of soluble species into backfill and then into rock. The calculation of release rates directly into rock is a special case. Section 4 presents numerical illustrations of the analytic results.

\section{DISSOLUTION OF FISSION PRODUCT SPECIES}

As fission product species are formed in $\mathrm{UO}_{2}$-based nuclear fuel, many of them are insoluble in $\mathrm{UO}_{2}$ and form secondary phases within $\mathrm{UO}_{2}$ fuel [Johnson and Shoesmith 1988]. Thus the dissolution of such species may not be controlled by the dissolution of the $\mathrm{UO}_{2}$ matrix.

Studies have shown that if the fuel irradiation temperatures exceed $1000^{\circ} \mathrm{C}$, the diffusion coefficients of fission product species incompatible with the $\mathrm{UO}_{2}$ lattice increase to such an extent that there is accumulation of volatile fission products in inter- and intragranular pores, and fission product species at grain boundaries. As cracks in the fuel pellets proprogate, and join intergranular pores, there is release of volatile fission product species to void spaces in the fuel rod, in the fuel-clad gap, and ultimately in the phenum.

Leaching experiments on spent fuel show that ${ }^{137} \mathrm{Cs}$ and ${ }^{129} \mathrm{I}$ are dissolved rapidly when the spent fuel is exposed to water [Garisto et al. 1989; Wilson 1990]. This is attributed to the dissolution of fission product species that have migrated to void spaces and gaps within $\mathrm{UO}_{2}$ fuel, referred to as "gap inventory fraction." Long-term leaching experiments show that the dissolution rate of fission product species remains elevated for years, due to water dissolving soluble fission products that have accumulated at grain boundaries of the uranium dioxide. The fraction of a given fission-product that can be released directly from grain boundaries is referred to as the "grain boundary release fraction." In this analysis we conservatively sum the instant release fraction and the grain-boundary release fraction into an "instant release fraction."

Leaching experiments in oxic waters show that ${ }^{99} \mathrm{Tc}$ has an instant release fraction.

In this analysis we assume that the remainder of the soluble species within the uranium dioxide matrix are released congruently with the dissolution of the matrix. The rate of matrix dissolution is cisumed here to be controlled by uranium solubility and by the rate of diffusion of dissolved uranium into surrounding rock. 
Reference waste package designs are for right circular cylinders, of sufficient length to accommodate intact spent-fuel assemblies, and of diameter so that several assemblies can fit into one package. The packages will include internal structures, such as spacers and fuel dividers to provide mechanical stability and facilitate loading (Figure 1). All packages are expected to be filled with an inert gas such as argon. In these packages, the internal space occupied by argon can be up to $80 \%$ because the void ratio in fuel assemblies is designed to be about $70 \%$ to $80 \%$, and the spacers do not occupy significantly more bulk. This void space, when flooded, forms the basis of the void space or gap in the model of this study. This void space is in the most intimate contact with the waste.

\section{ANALYSIS}

\subsection{TRANSPORT OF SOLUBLE SPECIES INTO BACKFILL AND ROCK}

We assume that once groundwater has penetrated a waste package it can readily dissolve the instant-release fraction of soluble fission products and that it can begin to dissolve the uranium-dioxide fuel matrix, thereby releasing additional soluble fission products. Presence of fuel cladding is conservatively neglected. Even though the soluble fission products can dissolve readily in the ground water within the waste package, the rate of release of these fission products to the surrounding rock will be limited, in part, by the rate of mass transfer of the dissolved species into the surrounding porous media.

The failed waste container and its corrosion products may present some mass-transfer resistance to the release of species dissolved in ground water that may have penetrated the waste container. However, we conservatively neglect the effect of the remaining container material or of its corrosion products and assume that the water containing dissolved fission products is in direct contact with the surrounding rock or with surrounding backfill.

The following analysis is for the mass-transfer rate of a readily soluble radioactive species, assuming instantaneous dissolution of the soluble species into a volume $V$ of ground water that has penetrated in the waste package voids at $t=0$, and assuming that the ground-water flow rate is small enough that mass-transfer into surrounding porous rock is controlled by molecular diffusion. The presence of a container is neglected.

We assume that a porous rock layer of thickness $L$ such as a backfill is in direct contact with the wellmixed gap liquid (Figure 2), that contains initially a specified quantity $N^{\circ}$ of a readily soluble species. One-dimensional Cartesian geometry is used in analyzing the diffusion of readily soluble species. The species migrate into the porous material under a concentration gradient. Assuming that advective transport is small compared with diffusive transport, the governing equations for transport are 


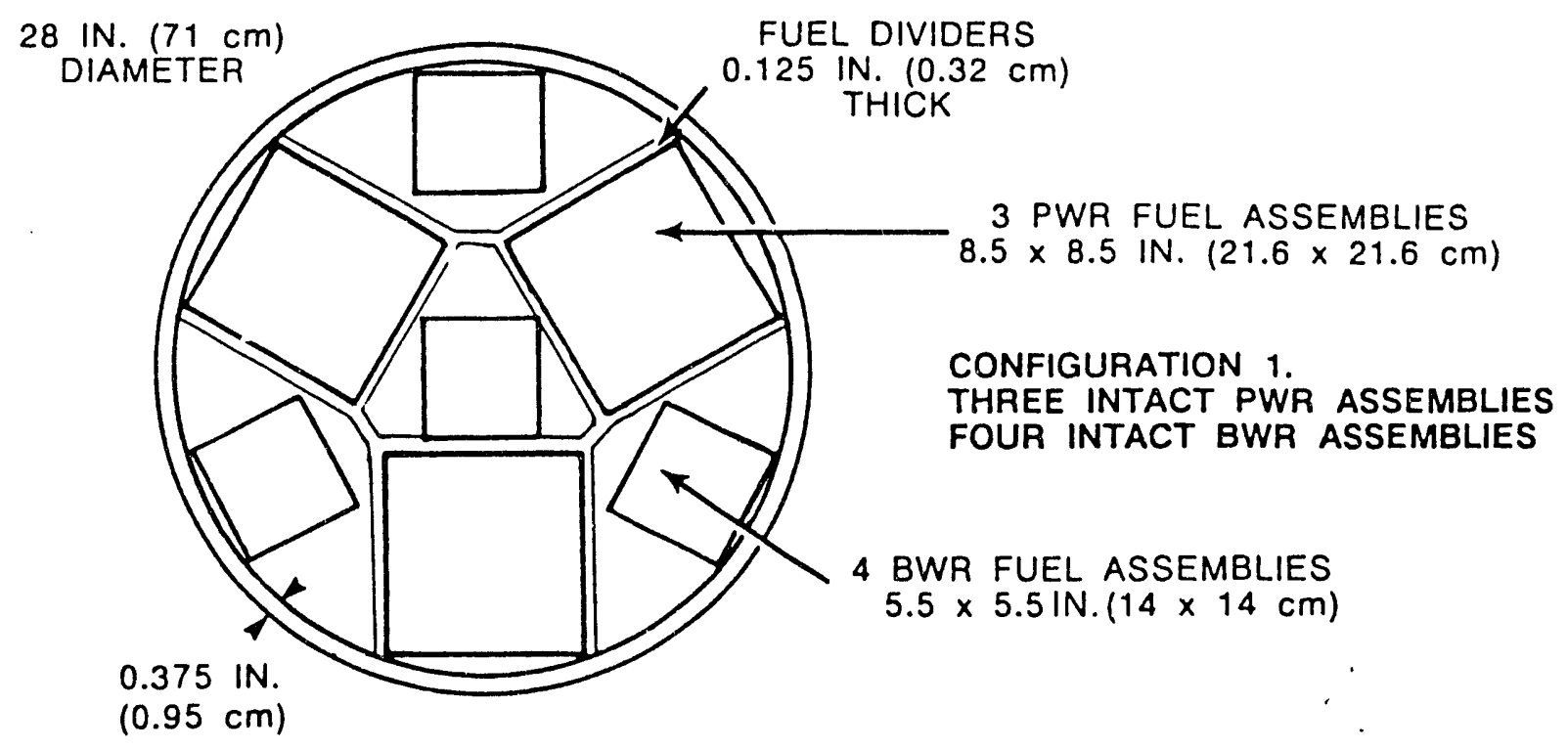

FIGURE 1. Typical Waste Package Cross Section.

$$
\begin{aligned}
& \frac{\partial N_{1}}{\partial t}=D_{1} \frac{\partial^{2} N_{1}}{\partial x^{2}}-\lambda N_{1} \quad-L<x<0 \quad t>0 \\
& \frac{\partial N_{2}}{\partial t}=D_{2} \frac{\hat{c}^{2} N_{2}}{\partial x^{2}}-\lambda N_{2} \quad 0<x<\infty \quad t>0
\end{aligned}
$$

where $N_{i}(x, t)$ for $i=1,2$ are the species concentration $\left[\mathrm{M} / \mathrm{L}^{3}\right]$ in the backfill layer and the adjacent rock respectively,

$D_{i} \equiv \frac{D}{K_{i}}$ for $i=1,2$ where $D$ is the diffusion cuefficient $\left[\mathrm{L}, \bar{R}^{2}\right]$ in the hackfili and rock,

$\lambda$ is the decay constant $\left[\mathrm{T}^{-1}\right]$, and

$K_{i}$ is the retardation coefficient of the species in backfill $i=1$ and rock $i=2$.

The initial conditions are

$$
\begin{array}{ll}
N_{1}(x, 0)=0 & -L<x<0 \\
N_{2}(x, 0)=0 & 0<x<\infty
\end{array}
$$

The boundary conditions are

$$
N_{1}(0, t)=N_{2}(0, t) \quad t>0
$$




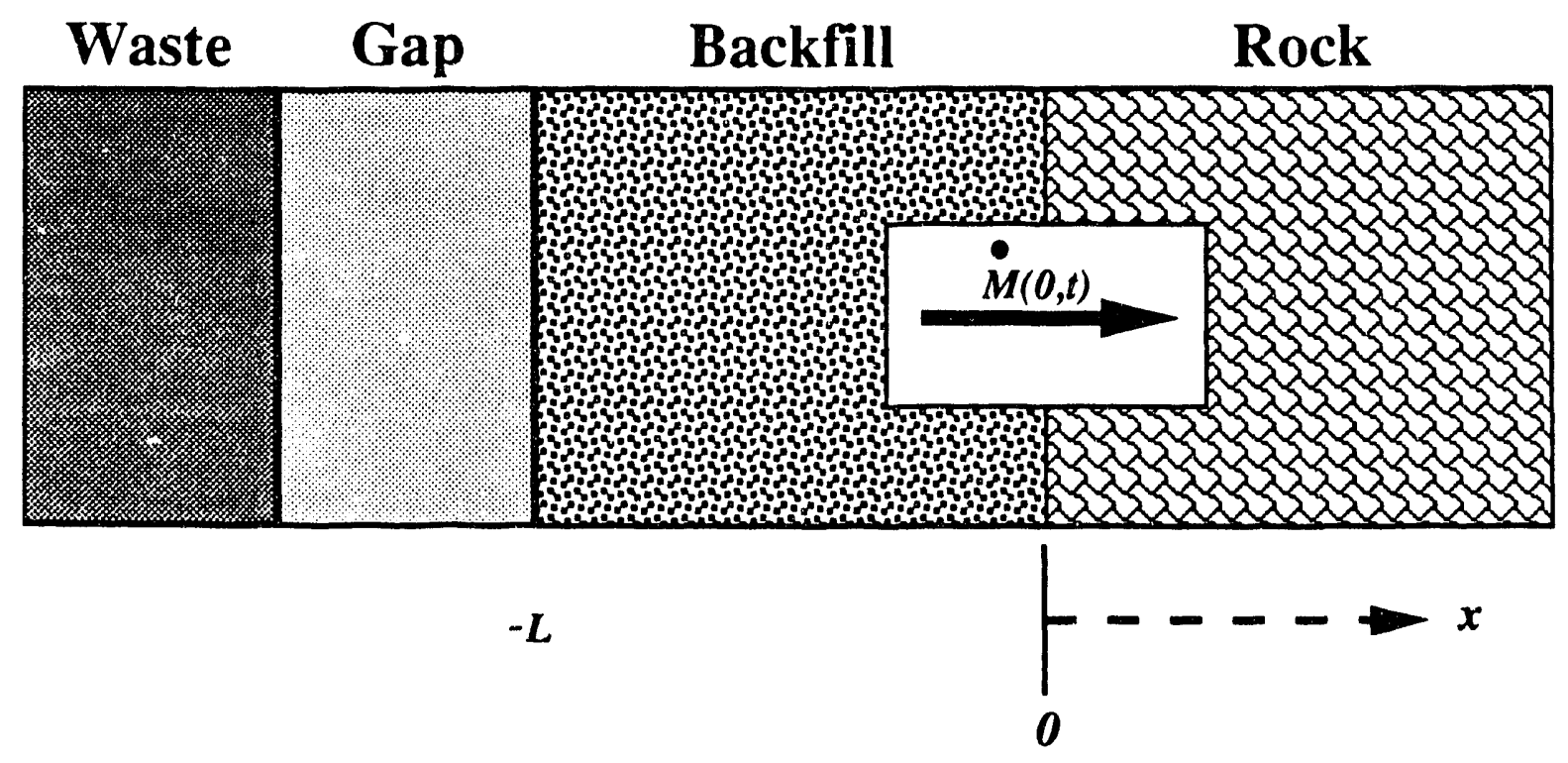

FIGURE 2. Release of Soluble Species into Backfll and Rock.

$$
\begin{gathered}
-\left.\epsilon_{1} D \frac{\partial N_{1}}{\partial x}\right|_{x=0}=-\left.\epsilon_{2} D \frac{\partial N_{2}}{\partial x}\right|_{x=0} \quad t>0 \\
N_{2}(\infty, t)=0 \quad t>0 \\
N_{1}(-L, 0)=N^{\circ}
\end{gathered}
$$

where $N^{\circ}$ is the presribed initial concentration in the gap. Eq. (5) and (6) describe continuity of concentration and diffusive flux at the backfill-rock interface. Eq. (7) sets the species concentration as $x \rightarrow \infty$.

In a well-mixed gap space, the species concentration everywhere is $N_{1}(-L, t)$. A mass balance in the gap yields

$$
V \frac{\partial N_{1}(-L, t)}{\partial t}=\dot{M}_{f}(t)+\left.S D \epsilon_{1} \frac{\partial N_{1}}{\partial x}\right|_{x=-L}-\lambda V N_{1}(-L, t) \quad t>0
$$

where $\dot{M}_{f}(t)$ is the specified external release rate of the species from the matrix $[\mathrm{M} / \mathrm{T}]$,

$\epsilon_{i}$ is the porosity, and

$S$ is the surface area of the gap or void $\left[\mathrm{L}^{2}\right]$.

Eq. (9) describes the rate of change of the mass of the species in volume $V$ in terms of the specified external release rate, the loss rates due to diffusion into the backfill and due to decay. 
The Laplace transform is used to solve (1)-(9) where

$$
\begin{gathered}
n_{i}(x, p)=\int_{0}^{\infty} e^{-p t} N_{i}(x, t) d t \quad i=1,2 \\
\dot{m}_{f}(p)=\int_{0}^{\infty} e^{-p t} \dot{M}_{f}(t) d t
\end{gathered}
$$

The transformed governing equations are

$$
\begin{array}{cc}
\frac{d^{2} n_{1}}{d x^{2}}=q_{1}^{2} n_{1} & -L<x<0 \\
\frac{d^{2} n_{2}}{d x^{2}}=q_{2}^{2} n_{2} & 0<x<\infty
\end{array}
$$

where

$$
q_{i}^{2} \equiv \frac{(p+\lambda)}{D_{i}}, \quad \text { for } i=1,2
$$

The transformed side conditions are

$$
\begin{gathered}
n_{1}(0, p)=n_{2}(0, p) \\
-\left.\epsilon_{1} D \frac{d n_{1}}{d x}\right|_{x=0}=-\left.\epsilon_{2} D \frac{d n_{2}}{d x}\right|_{x=0} \\
n_{2}(\infty, p)=0 \\
(p+\lambda) V n_{1}(-L, p)-\left.S D \epsilon_{1} \frac{d n_{1}}{d x}\right|_{x=-L}=V N^{\circ}+\dot{m}_{f}(p)
\end{gathered}
$$

Given (17), the solution to (13) is of the form

$$
n_{2}(x, p)=A e^{-q_{2} x}, \quad x>0
$$

Using (15) and (19), the solution to (12) is of the form

$$
n_{1}(x, p)=A \cosh \left(q_{1} x\right)+B \sinh \left(q_{1} x\right), \quad-L<x<0
$$

Eq. (16) and (18) are used to evaluate $A$ and $B$. From (19) and (20)

$$
\begin{gathered}
\frac{d n_{1}}{d x}=q_{1}\left[A \sinh \left(q_{1} x\right)+B \cosh \left(q_{1} x\right)\right] \\
\frac{d n_{2}}{d x}=-q_{2} A e^{-q_{2} x}
\end{gathered}
$$

and substituting the derivatives into (16) yields

$$
B=-\frac{1}{\delta} A
$$


where $\delta \equiv \frac{\epsilon_{1}}{\epsilon_{2}} \sqrt{\frac{K_{1}}{K_{2}}}$ From (18) results

$$
A=\frac{\delta L}{q_{1} D_{1} V} G(p)\left[V N^{0}+\dot{m}_{f}(p)\right]
$$

with the function $G(p)$ defined as

$$
G(p) \equiv \frac{1}{\left[q_{1} L+\gamma_{1} \delta\right] \sinh \left(q_{1} L\right)+\left[q_{1} L \delta+\gamma_{1}\right] \cosh \left(q_{1} L\right)}
$$

and $\gamma_{1} \equiv \frac{\epsilon_{1} K_{1} L S}{V}$. The solutions $n_{1}$ and $n_{2}$ can then be written

$$
\begin{gathered}
n_{1}(x, p)=\frac{\delta L}{q_{1} D_{1} V} G(p)\left[\cosh \left(q_{1} x\right)-\frac{1}{\delta} \sinh \left(q_{1} x\right)\right]\left[V N^{\circ}+\dot{m}_{f}(p)\right] \quad-L \leq x \leq 0 \\
n_{2}(x, p)=\frac{\delta L}{q_{1} D_{1} V} G(p) \exp \left(-q_{2} x\right)\left[V N^{\circ}+\dot{m}_{f}(p)\right] \quad 0 \leq x<\infty
\end{gathered}
$$

The principal quantity of interest is the mass transfer rate from the backfill into the rock

$$
\dot{M}(0, t)=-\left.D \epsilon_{1} S \frac{\partial N_{1}}{\partial x}\right|_{x=0} \quad t>0
$$

This quantity can be calculated from the transformed solution $n_{1}(x, p)$. The Laplace transform of $(28)$ is

$$
\dot{m}(0, p)=-\left.D \epsilon_{1} S \frac{d n_{1}}{d x}\right|_{x=0}
$$

so that with (26)

$$
\dot{m}(0, p)=\gamma_{1} G(p)\left[V N^{\circ}+\dot{m}_{f}(p)\right]
$$

The inverse of (30) in terms of $g(t)$, the yet-to-be-calculated inverse of $G(p)$, yields the desired mass transfer of the species into the rock

$$
\dot{M}(0, t)=\gamma_{1} V N^{\circ} g(t)+\gamma_{1} \int_{0}^{t} \dot{M}_{f}(t-\tau) g(\tau) d \tau \quad t>0
$$

The first term represents the contribution from the initial gap inventory and the second term represents the contribution due to the dissolution of the matrix.

The complicated function $G(p)$ can be inverted exactly, leading to a series representation in Laguerre polynomials. However, it is also possible to obtain analytic solutions for small and large times, as well as an 
approximate solution covering the entire time range. For this express $G(p)$ using (25), in terms of exponential functions

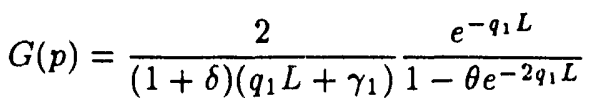

where

$$
\theta \equiv \frac{1-\delta}{1+\delta} \frac{q_{1} L-\gamma_{1}}{q_{1} L+\gamma_{1}}
$$

and expand (32) in powers of $e^{-2 q_{1} L}$. Hence,

$$
G(p)=\frac{2}{(1+\delta)\left(q_{1} L+\gamma_{1}\right)} \sum_{n=0}^{\infty} \theta^{n} e^{-(2 n+1) q_{1} L}, \quad\left|e^{-2 q_{1} L}\right|<1
$$

For early time approximate $\left(q_{1} L-\gamma_{1}\right) /\left(q_{1} L+\gamma_{1}\right)$ by 1 while for large time $\left(q_{1} L-\gamma_{1}\right) /\left(q_{1} L+\gamma_{1}\right)$ is replaced by -1 .

With help of the translation theorem, the inverse of

$$
\frac{e^{-(2 n+1) q_{1} L}}{\left(q_{1} L+\gamma_{1}\right)}
$$

is given by [Erdélyi et al. 1954]

$$
\frac{\sqrt{D_{1}}}{L} e^{-\lambda t} \exp \left(-\frac{(2 n+1)^{2} L^{2}}{4 D_{1} t}\right)\left\{\frac{1}{\sqrt{\pi t}}-\frac{\gamma_{1} \sqrt{D_{1}}}{L} \mathrm{H}\left(\beta_{n}^{2}\right)\right\}, \quad t>0
$$

where

$$
\beta_{n}^{2} \equiv \frac{(2 n+1) L}{2 \sqrt{D_{1} t}}+\frac{\gamma_{1} \sqrt{D_{1} t}}{L}
$$

The function

$$
\mathbf{H}\left(u^{2}\right) \equiv e^{u^{2}} \operatorname{erfc}(u)
$$

monotonically decreases from unity at $u=0$ to zero as $u \rightarrow \infty$ and can be computed accurately and quickly by a rational approximation routine. Hence the approximate inversions of $G(p)$ are

$$
\begin{aligned}
& g(t)=\frac{2 \sqrt{D_{1}}}{(1+\delta) L} e^{-\lambda t} \sum_{n=0}^{\infty}\left(\frac{1-\delta}{1+\delta}\right)^{n} \exp \left(-\frac{(2 n+1)^{2} L^{2}}{4 D_{1} t}\right)\left\{\frac{1}{\sqrt{\pi t}}-\frac{\gamma_{1} \sqrt{D_{1}}}{L} \mathrm{H}\left(\beta_{n}^{2}\right)\right\}, \quad \text { for small } t \\
& g(t)=\frac{2 \sqrt{D_{1}}}{(1+\delta) L} e^{-\lambda t} \sum_{n=0}^{\infty}\left(\frac{\delta-1}{1+\delta}\right)^{n} \exp \left(-\frac{(2 n+1)^{2} L^{2}}{4 D_{1} t}\right)\left\{\frac{1}{\sqrt{\pi t}}-\frac{\gamma_{1} \sqrt{D_{1}}}{L} \mathrm{H}\left(\beta_{n}^{2}\right)\right\}, \quad \text { for large } t
\end{aligned}
$$

It was discovered that (39) together with (31) for the case of $\dot{M}_{f}=0$ yields an approximate solution which covers the entire time range of physical interest to a satisfactory degree. This is shown in Kang [1989], by 
comparing these results with a numerical inversion of $G(p)$. This is in part due to the fact that $(38)$ and (39) coincide for small $t$ because only the first term $(n=0)$ dominates in both series and these terms are identical.

For the case of no matrix contribution, or $\dot{M}_{j}=0$ in (31), the approximate solution that covers the entire time range of physical interest to a satisfactory degree is

$$
\dot{M}(0, t)=\epsilon_{1} K_{1} L S N^{\circ}\left[\frac{2 \sqrt{D_{1}}}{(1+\delta) L} e^{-\lambda t} \sum_{n=0}^{\infty}\left(\frac{\delta-1}{5+1}\right)^{n} \exp \left(-\frac{(2 n+1)^{2} L^{2}}{4 D_{1} t}\right)\left\{\frac{1}{\sqrt{\pi t}}-\frac{\gamma_{1} \sqrt{D_{1}}}{L} \mathrm{H}\left(\beta_{n}^{2}\right)\right\}\right], t>0
$$

If the 1000-year inventory of the species is $M^{\star}$, and if the U.S. Nuclear Regulatory Commission subsystem perfurmance requirement for the engineered barrier system is applied for an individual package, then the fractional release rate can be computed by

$$
f(t)=\frac{\dot{M}(0, t)}{M^{\star}}, \quad t>0
$$

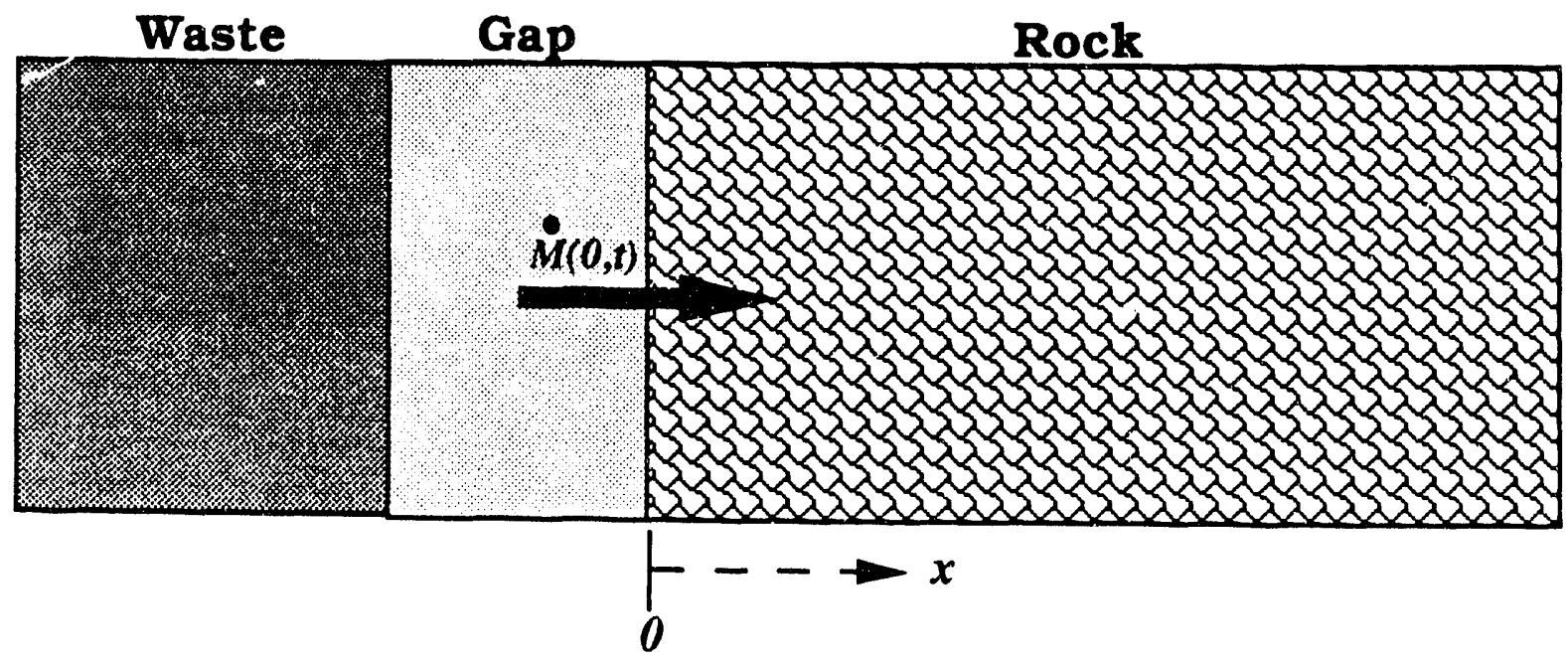

FIGURE 3. Release of Soluble Species into Rock.

\subsection{TRANSPORT OF SOLUBLE SPECIES INTO ROCK}

Next we consider the case of the transport of soluble species directly into rock, Figure 3 . Here $L=0, \delta=1$ and there is no need to use subscripted variables. The Laplace-transformed solution for the species in the rock is

$$
n(x, p)=\psi(x, p)\left[N^{\circ}+\frac{1}{V} \dot{m}_{f}(p)\right] \quad 0<x<\infty
$$


where

$$
\psi(x, p) \equiv \frac{e^{-\sqrt{p+\lambda} \sqrt{K x^{2} / D}}}{\sqrt{p+\lambda\left(\sqrt{p+\lambda}+\frac{\epsilon S \sqrt{K D}}{V}\right)}} \quad 0<x<\infty
$$

With help of the translation theorem, the inverse transform of $\psi(x, p)$ is given by [Erdélyi et al. 1954]

$$
\Psi(x, t)=e^{-\lambda t} \exp \left(-\frac{K x^{2}}{4 D t}\right) \mathrm{H}\left[\left(\frac{\epsilon S \sqrt{K D t}}{V}+\sqrt{\frac{K x^{2}}{4 D t}}\right)^{2}\right], \quad 0<x<\infty, \quad t>0
$$

The concentration field $N(x, t)$ is given by the inverse transform of (42) which is expressed here in terms of $\Psi(x, t)$

$$
N(x, t)=N^{\circ} \Psi(x, t)+\frac{1}{V} \int_{0}^{t} \dot{M}_{f}(t-\tau) \Psi(x, \tau) d \tau, \quad 0<x<\infty \quad t>0
$$

The first term represents the contribution from the initial gap inventory and the second term represents the contribution due to ongoing leaching of the waste form.

The concentration in the gap for the case with no backtill is equal to $N(0, t)$ and can be obtained by setting $x=0$ in (45). The release rate into the host rock can be obtained by setting $\delta=1$ and $L=0$ in (31) and using (38) or (39) for $g(t)$ with the result

$$
\begin{aligned}
\dot{M}(0, t) & =\epsilon K S N^{0} e^{-\lambda t}\left\{\sqrt{\frac{D}{\pi K t}}-\frac{\epsilon S D}{V} \mathrm{H}\left(\frac{\epsilon^{2} S^{2} D K t}{V^{2}}\right)\right\} \\
& +\frac{\epsilon K S}{V} \int_{0}^{t} \dot{M}_{f}(t-\tau) e^{-\lambda \tau}\left\{\sqrt{\frac{D}{\pi K \tau}}-\frac{\epsilon S D}{V}-\mathrm{H}\left(\frac{\epsilon^{2} S^{2} D K \tau}{V^{2}}\right)\right\} d \tau, \quad t>0
\end{aligned}
$$

\section{NUMERICAL ILUUSTRATIONS}

In this Section we illustrate the above analytic results, using conditions typical of geologic disposal of nuclear waste. Two illustrations are offered:

Case 1: Calculation of release rates into backfill and basalt with no contribution from the waste matrix; and Case 2: Calculation of release rates into salt directly, with continuing contribution from the waste matrix.

Table I lists dimensions of the waste packages. Table II lists assumed properties of the rock. Table III lists characteristics of the nuclides used in the calculations.

\section{Case 1}

We illustrate the use of (40) for the geometry in Figure 2. It is assumed that the ground water fills the void or gap in the waste package and water contacts the interior of spent-fuel rods, and one percent of the tutal inventory of cesium, iodine and technetium is rapidly dissolvad into the "void-water." The "void-water" has 
the volume of $0.45 \mathrm{~m}^{3}$ which is equal to the difference of the volume of the waste canister and the total volume of enclosed fuel rods. Ground-water flow is assumed to be small enough so that the mass transfer through backfill and rock is controlled by a molecular diffusion, and the value of the diffusion coefficient is assumed to be $10^{-5} \mathrm{~cm}^{2} / \mathrm{s}$ for both backfill and basalt. The thickness of the backfill is $15 \mathrm{~cm}$ and the porosities of the backfill and basalt are 0.3 and 0.01 , respectively. The fractional release rates at the backfill/basalt interface are computed, normalized to the initial inventory in order to display the results on the same graph.

Table I. Waste Package Dimensions, Spent Fuel from Pressurized Water Reactors

\begin{tabular}{|l|c|c|c|}
\hline \multicolumn{2}{|c|}{ Waste Package In } & Rock & Salt \\
\hline Height & $(\mathrm{m})$ & 4.37 & 3.68 \\
\hline Radius & $(\mathrm{m})$ & 0.49 & 0.29 \\
\hline Thickness of Backfill & $(\mathrm{cm})$ & 15.0 & 10.0 \\
\hline Volume of Gap & $\mathrm{m}^{3}$ & 0.45 & 0.45 \\
\hline \multicolumn{2}{|c|}{ Source } & Yung et al. 1987 & USDOE 1986 \\
\hline
\end{tabular}

Table II. Rock Properties

\begin{tabular}{|l|c|c|c|c|}
\hline \multicolumn{2}{|c|}{ In } & Rock & Backfill & \multicolumn{1}{c|}{ Salt } \\
\hline Diffusion Coefficient & $\mathrm{cm}^{2} / \mathrm{s}$ & $1.0 \times 10^{-5}$ & $1.0 \times 10^{-5}$ & $1 \times 10^{-7}$ \\
\hline Porosity & & 0.01 & 0.3 & 0.001 \\
\hline
\end{tabular}

Table III. Characteristics of the Nuclides Studied

\begin{tabular}{|l|c|c|c|c|}
\hline & Cs-135 & Cs-137 & I-129 & Tc-99 \\
\hline Retardation Coefficient in Basalt & 19800 & 19800 & 1 & 1 \\
\hline Retardation Coefficient in Salt & 10 & 10 & 1 & 1 \\
\hline Decay Constant $\left(\mathrm{a}^{-1}\right)$ & $3.0 \times 10^{-7}$ & $2.3 \times 10^{-2}$ & $4.41 \times 10^{-8}$ & $3.22 \times 10^{-7}$ \\
\hline Calculated USNRC Release Rate Limit $\left(\mathrm{a}^{-1}\right)$ & $5.0 \times 10^{-5}$ & $2.0 \times 10^{-10}$ & $5.5 \times 10^{-4}$ & $1.0 \times 10^{-5}$ \\
\hline
\end{tabular}

In this calculation it is assumed that the distribution coefficients $K_{d}$ are $100 \mathrm{~cm}^{3} / \mathrm{g}$ for ceslum and zero for iodine, and $\rho$ the density of the solid phase, i.e., rock and backfill, is $2 \mathrm{~g} / \mathrm{cm}^{3}$. The retardation coefficient is computed as

$$
K=1+\rho K_{d} \frac{1-\epsilon}{\epsilon}
$$

A simple computer program has been implemented for (40) to calculate the fractional release rates of soluble 
species [Kang and Lee 1989].

Figure 4 shows the time-dependent fractional release rates of ${ }^{135} \mathrm{Cs},{ }^{137} \mathrm{Cs},{ }^{99} \mathrm{Tc}$ and ${ }^{129} \mathrm{I}$ at the backfill/basalt interface, normalized to initial inventory of each species. The non-sorbing ${ }^{99} \mathrm{Tc}$ and ${ }^{129} \mathrm{I}$ arrive at the backfill/rock interface earlier than the strongly sorbing cesium. ${ }^{135} \mathrm{Cs}$ and ${ }^{137} \mathrm{Cs}$ arrive simultaneously, and the release rates are the same in early times because they have the same retardation coefficients. However, because the half-life of the ${ }^{137} \mathrm{Cs}$ is much shorter than that of ${ }^{135} \mathrm{Cs}$, the release rate of ${ }^{137} \mathrm{Cs}$ decreases rapidly as time goes on. In early times the release rate of ${ }^{129} \mathrm{I}$ is higher than that of ${ }^{135} \mathrm{Cs}$, but after about 1000 years, the release rate of ${ }^{135} \mathrm{Cs}$ becomes higher than that of ${ }^{129} \mathrm{I}$. The fractional release rate of ${ }^{99} \mathrm{Tc}$ becomes distinguishable from that of ${ }^{129} \mathrm{I}$ only after $10^{5}$ years, due to the decay of ${ }^{99} \mathrm{Tc}$. For this very conservative analysis of bare waste form in water-saturated rock, the only species that fails to meet the USNRC subsystem performance objective on an individual container basis is ${ }^{99} \mathrm{Tc}$. With a suitable timedistribution of container failures, ${ }^{99} \mathrm{Tc}$ could meet the subsystem performance objective [Kim, Chambré and Pigiord 1985].

We might ask how thick a backfill would have to be for bare waste to meet the release rate criteron for ${ }^{99} \mathrm{Tc}$. Figure 5 shows the fractional release rate of ${ }^{99} \mathrm{Tc}$ as a function of time with the backfill thickness as a parameter. Thicker backfills delay arrival at the backfill/basalt interface and also allow greater decay in the backfill, and so the peak release rate decreases. For ${ }^{99} \mathrm{Tc}$, a backfill of $120 \mathrm{~cm}$ would be needed for bare waste to meet the release rate criterion at all times. Figure 5 illustrates the non-proportional relation between backfill thickness and peak fractional release rate.

\section{Case 2}

In this case we illustrate the use of (46) with a matrix contribution. There is no backfill here (Figure 3 ) and the radionuclides are assumed to be released instantly into the water that penetrates a water container. Hwang et al. [1988] have shown that for flow regimes near waste packages in high-level waste repository in salt, release $r$ es can be calculated using diffusion as the dominant transport mechanism. To evaluate the integral in (46) we need an expression for $\dot{M}_{f}$. T? : mass transfer rate of the dominant species or matrix from a spherical waste solid is given in eq. (33) of Chapter 8 of Chambré et al. [1985],

$$
\dot{M}_{c}(t)=\frac{D c_{s} \epsilon}{R}\left\{1+\sqrt{\frac{K_{c} R^{2}}{\pi D t}} e^{-\lambda_{M} t}+\sqrt{\frac{\lambda_{M} K_{c} R^{2}}{D}} \operatorname{erf}\left(\sqrt{\lambda_{M} t}\right)\right\}, \quad t>0
$$

where $\dot{M}_{c}(t)$ is the mass transfer rate of the controller or matrix species,

$R$ is the radius of the waste sphere,

$K_{c}$ is the retardation coefficient of the dominant species and

$c_{s}$ is the solubility of the dominant species in the matrix.

The dominant species in the matrix, $\mathrm{UO}_{2}$ in spent fuel or silica in borosilicate glass, has very small decay 


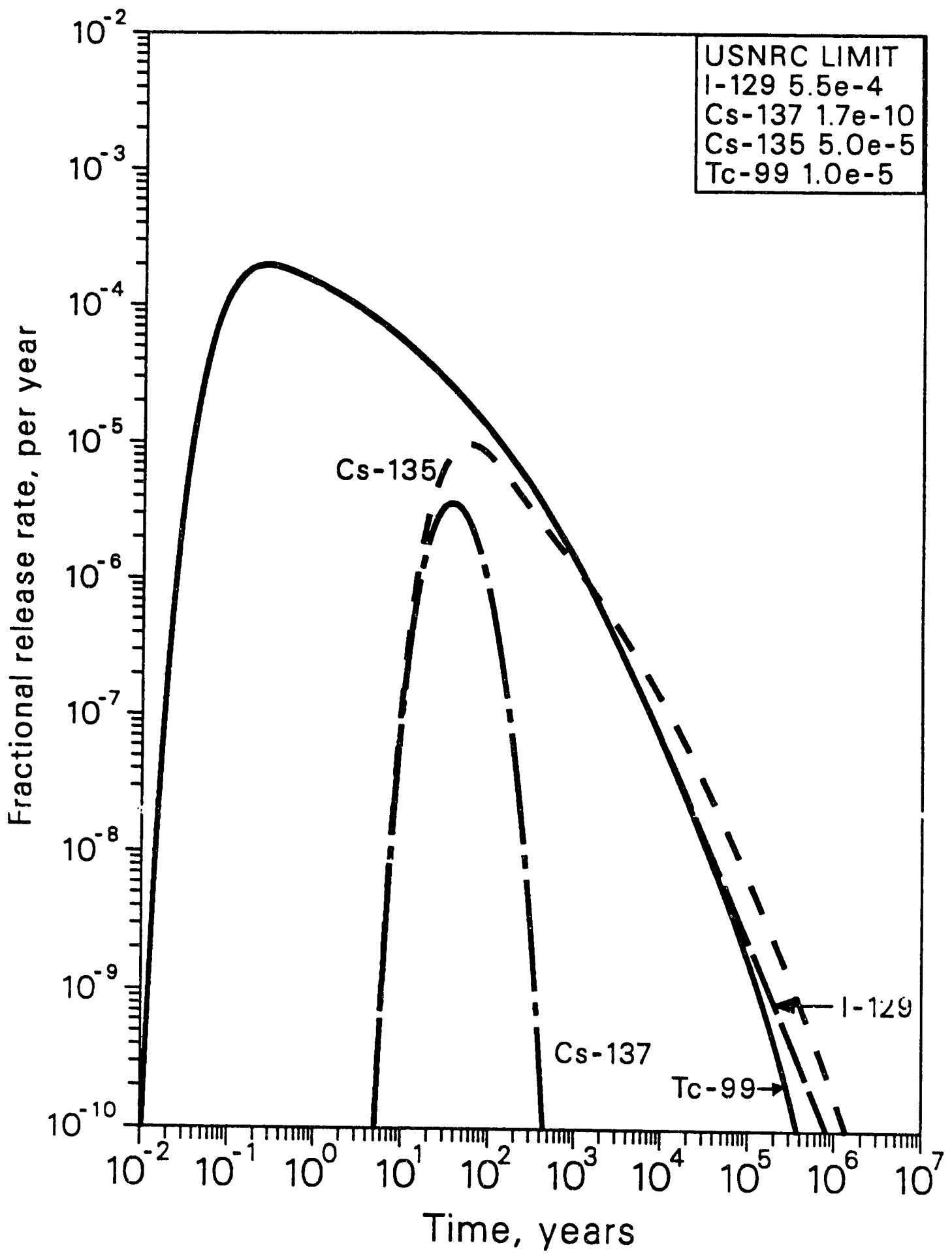
FIGURE 4. Fractional release rates of ${ }^{99} \mathrm{Tc},{ }^{135} \mathrm{Cs},{ }^{137} \mathrm{Cs}$ and ${ }^{129} \mathrm{I}$ through $30 \mathrm{~cm}$ of backfill, at the
backfill/rock interface, normalized to initial inventory. 


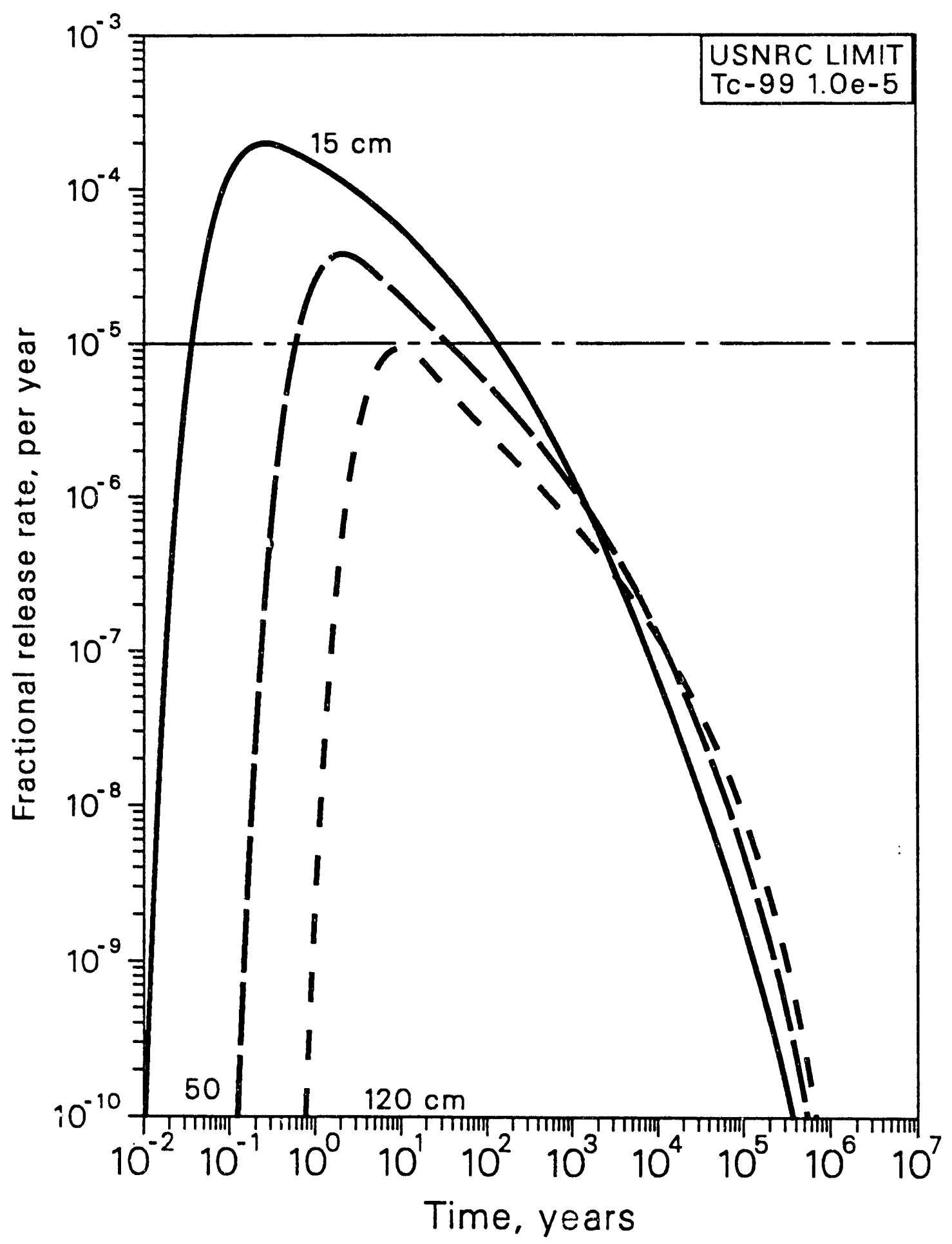

FIGURE 5. Fractional release rate of ${ }^{99} \mathrm{Tc}$, normalized to its initial inventory, as a function of backfill thickness. 
rates, and therefore we can neglect decay $\left(\lambda_{M}=0\right)$. Moreover, in the planar geometry of the governing equations (1) through (9), we let $R \rightarrow \infty$ to obtain

$$
\dot{M}_{c}(t)=c_{0} \epsilon \sqrt{\frac{K_{c} D}{\pi t}}, \quad t>0
$$

Using the congruent dissolution assumption

$$
\frac{\dot{M}_{f}(t)}{\dot{M}_{c}(t)}=\frac{M(t)}{M_{c}(t)}=\frac{M^{\circ} e^{-\lambda t}}{M_{c}^{\circ}}, \quad t>0
$$

where $M(t)$ is the species inventory at $t, M^{0}$ is the initial inventory of the species in the waste package, and $M_{c}^{0}$ is the initial inventory of the controller species in the waste package and $M_{c}(t)$ is the matrix inventory at $t$.

Rearranging we obtain

$$
\dot{M}_{f}=c_{s} \epsilon \sqrt{\frac{K_{c} D}{\pi t}} \frac{M^{\circ}}{M_{c}^{\circ}} e^{-\lambda t}, \quad t>0
$$

The expression (51) can be inserted into (46) and integrated numerically. This was done in Kim et al. [1986] and the computer program UCB-NE-107 [Lee 1989].

Figure 6 shows the calculated fractional release rates of ${ }^{99} \mathrm{Tc},{ }^{135} \mathrm{Cs},{ }^{137} \mathrm{Cs}$ and ${ }^{129} \mathrm{I}$ to the surrounding salt as a function of time since the beginning of release. In Figure 6, all release rates are shown in terms of initial inventories so that isotopes of different decay rates can be shown on the same figure. Release rates in terms of 1000 -year inventories can be readily calculated from the curves.

The total fractional release rate curves for ${ }^{135} \mathrm{Cs}$ and ${ }^{137} \mathrm{Cs}$, in Figure 6, begin at a higher fractional release than those for ${ }^{129} \mathrm{I}$ and ${ }^{99} \mathrm{Tc}$, because of the greater sorption of cesium in the surrounding rock. The release rate of ${ }^{137} \mathrm{Cs}$ decreases rapidly, due to decay. The fractional release rate of ${ }^{129} \mathrm{I}$ and ${ }^{99} \mathrm{Tc}$ are identical for up to several hundred thousand years because they lack sorption. Their release rates become different when the decay of ${ }^{99} \mathrm{Tc}$ becomes apparent. At late times, the fractional release rate of ${ }^{135} \mathrm{Cs}$ becomes lower than that of ${ }^{129} \mathrm{I}$, also due to decay. If the fraction of cesium that is instantly released into the gap water is only a few percent, the calculated release limit for ${ }^{135} \mathrm{Cs}$ is exceeded only for a few years, assuming that all waste packages fail at the same time. A distribution of container failures over time can result in a repositoryaverage fractional release rate of cesium below the calculated limit, for instant release fractions of a few percent [Kim, Chambré and Pigford 1985].

Figure 6 also shows the contribution from the waste matrix by congruent dissolution. The matrix release rates here have been calculated using an uranium solubility of $50 \mathrm{~g} / \mathrm{m}^{3}$. The pattern of the matrix release rates mirrors that of the total release rates. With these parameters, the early contribution from gap inventory 


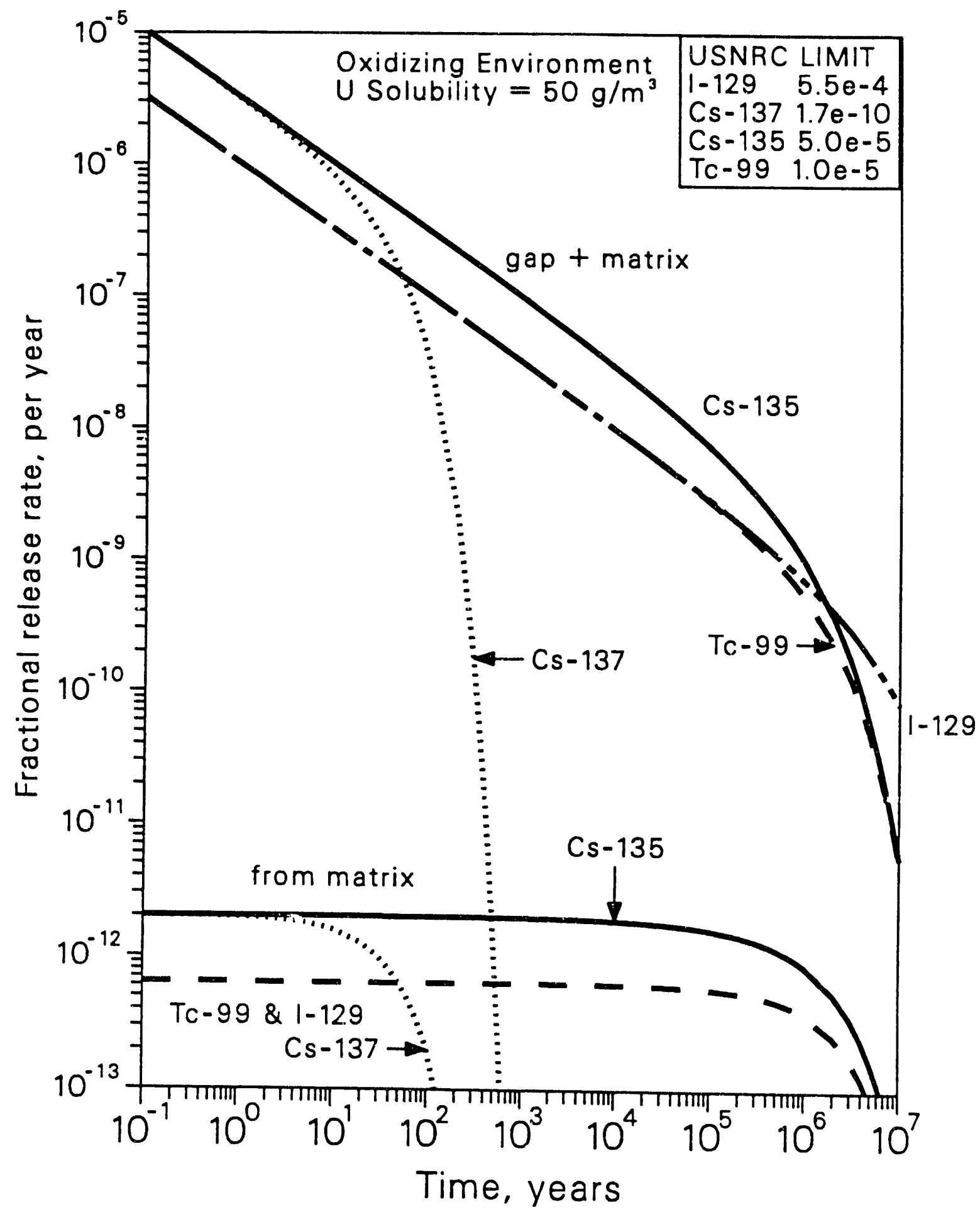

FIGURE 6. Gap and matrix fractional release rates of ${ }^{99} \mathrm{Tc},{ }^{135} \mathrm{Cs},{ }^{137} \mathrm{Cs}$ and ${ }^{129} \mathrm{I}$ directly into rock as a function of time. 
is more than $10^{6}$-fold greater than the matrix contribution. Matrix contribution does not become important until very late times, or if matrix solubility is very high.

\section{CONCLUSIONS}

The transient mass transport of a soluble species directly into rock and through a backfill into a surrounding rock is studied. Analytic solutions have been given for the transport of this class of important radioactive species. For transport directly into rock, an exact solution is given, and economic implementation of the solutions as computer codes is available [Lee 1989; Kang and Lee 1989'.

For transport through backfill an approximate solution that is valid for all time is given. This approximate solution has been compared with the early-time approximate solution, the large-time asymptotic solution. and the solution obtained from the numerical inversion of the Laplace transform covering the entire time span. The approximate solution is an adequate calculational tool to estimate the release rate for all cases.

In the numerical illustrations we calculated fractional release rates of ${ }^{99} \mathrm{Tc},{ }^{129} \mathrm{I},{ }^{135} \mathrm{Cs}$ and ${ }^{137} \mathrm{Cs}$ directly into rock, and into rock through backfill for different combination of instant release fraction and matrix contribution. Non-sorbing species such as ${ }^{99} \mathrm{Tc}$ and ${ }^{129} \mathrm{I}$ arrive at the backfill-rock interface first, and ${ }^{135} \mathrm{Cs}$ and ${ }^{137} \mathrm{Cs}$ arrive together, because the isotopes of cesium have identical retardation properties. The short half life of ${ }^{137} \mathrm{Cs}$ causes rapid decline of its fractional release rate several hundred years following emplacement. For direct release into the rock, the contribution from release congruent with matrix dissolution is more than six orders of magnitude below that from the instant release fraction of one percent of the species inventory.

The backfill serves to delay the arrival of radionuclides at the backfill-rock interface. However, the thickness of the backfill produces a non-proportional reduction in the peak fractional release rate.

\section{REFERENCES}

P. L. Chambré, T. H. Pigford, Y. Sato, A. Fujita, H. Lung, S. Zavoshy and R. Kobayashi, 1982. Anaiytical Performance Models, LBL-14842, Lawrence Berkeley Laboratory, Berkeley, CA.

P. L. Chambré, T. H. Pigford, W.W.-L. Lee, J. Ahn, S. Kajiwara, C. L. Kim, H. Kimura, H. Lung, W.

J. Williams and S. J. Zavoshy, 1985. Mass Transfer and Transport in a Geologic Environment,LBL-19430, Lawrence Berkeley Laboratory, Berkeley, CA.

A. Erdélyi, W. Magnus, F. Oberhettinger and F. G. Tricomi, 1954. Tables of Integral Transforms, New York: McGraw-Hill.

N. C. Garisto, E. R. Vance, S. Stroes-Gascoyne, and L. H. Johnson, 1989. Instant-Release Fractions for the Assessment of Used Nuclear Fuel Disposal, Report AECL-9892, AECL, Pinawa, Manitoba.

Y. Hwang, W. W.-L. Lee, P. L. Chambré and T. H. Pigford, 1988. Release Rates in Salt by Diffusion, Report 
LBL-25767, Lawrence Berkeley Laboratory, Berkeley, CA.

L.H. Johnson and D.W. Shoesmith, 1988. "Spent Fuel," in W. Lutze and R.C. Ewing (eds.), Radioactive Waste Forms for the Future, Amsterdam: Elsevier.

C.-H. Kang, 1989. "Mass Transfer and Transport of Radionuclides Through Backfill in a Geologic Nuclear Waste Repository," Ph. D., University of California, Berkeley.

C. H. Kang and W. W.-L. Lee, 1989. UCB-NE-108 User's Manual, LBL-27044, Lawrence Berkeley Laboratory, Berkeley, CA.

C. L. Kim, P. L. Chambré and T. H. Pigford, 1985. "Radionuclide Release Rates as Affected by Container Failure Probability," Trans. Am. Nuc. Soc., 50, 136.

C. L. Kim, P. L. Chambré and T. H. Pigford, 1986. "Mass-Transfer Limited Release of a Soluble Waste Species," Trans. Am. Nuc. Soc., 52, 80.

W. W.-L. Lee, 1989. UCB-NE-107 User's Manual, LBL-26672, Lawrence Berkeley Laboratory, Berkeley, $\mathrm{CA}$.

M.J. Nicol and C.R.S. Needes, 1975. "The Anodic Dissolution of Uranium Dioxide-I. in Perchlorate Solutions," Electrochim. Acta, 20, 585.

M.J. Nicol and C.R.S. Needes, 1977. "The Anodic Dissolution of Uranium Dioxide-II. in Carbonate Solutions," Electrochim. Acta, 22, 1381.

U.S. Department of Energy (DOE), 1986. Environmental Assessment, Deaf Smith County Site, Texas, DOE/RW 0069.

C. N. Wilson, 1990. "Results from NNWSI Series 3 Spent Fuel Dissolution Tests," PNL-7170.:

S. C. Yung, C. F. McLane, R. P. Anantatmula, R. T. Toyooka, and W. K. Terry, 1987. Waste Package Preliminary Reliability Analysis Report, Report SD-BWI-TI-287, Rockwell. 

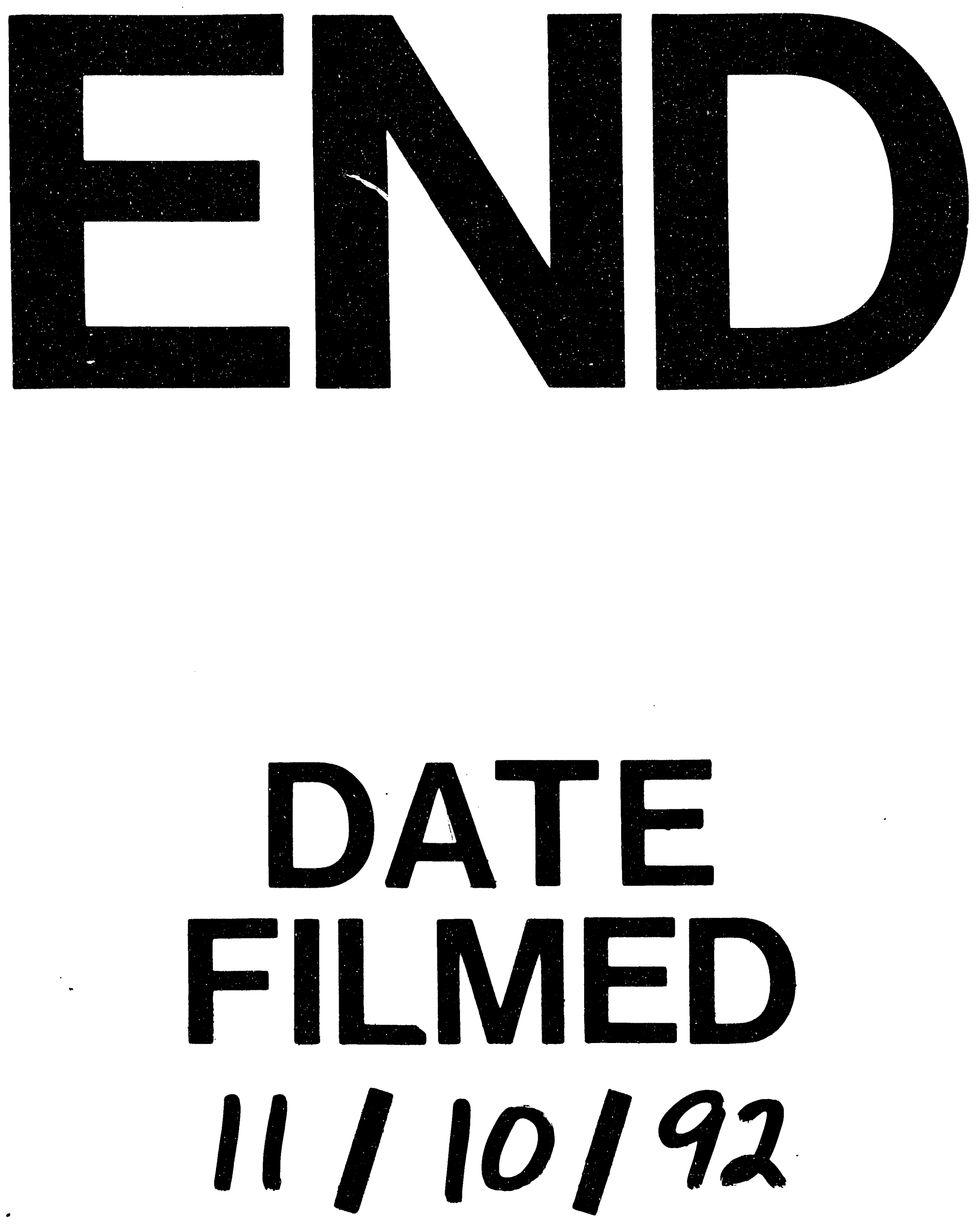

1 
